\title{
Climatic Potential for Natural Ventilation
}

\author{
Francesco Causone
}

Department of Energy, Politecnico di Milano, Milano, Italy

Francesco Causone, $\mathrm{PhD}$

Assistant Professor

Politecnico di Milano, Energy Department

Via Lambruschini 4, 20156 Milano (Italy)

tel. +3902 23998621

Email: francesco.causone@polimi.it 


\section{Climatic Potential for Natural Ventilation}

Naturally ventilated buildings have been widely adopted, because they may increase user satisfaction and well-being while reducing energy consumption due to HVAC systems. Analysis and simulation tools are required at different design stages to support the usage of natural ventilation. Three main levels of analysis/design are identified: climatic analysis, building/system design, and comfort assessment.

Focusing on the first level of analysis, this paper proposes a methodology to evaluate the climatic potential for natural ventilation. The methodology does not address a particular ventilation strategy or system. It includes adaptive comfort models and introduces an approach that integrates humidity constraints. The methodology can be applied at the conceptual building design stage to orient designers by providing them with a benchmark for the proceeding design phases or as a tool to contrast different climates. Calculation examples are reported.

Keywords: natural ventilation; climatic potential; adaptive comfort; climatic analysis; weather analysis; humidity; passive cooling

\section{1-Introduction}

In recent decades, the number of naturally ventilated and mixed-mode buildings has substantially increased, especially high-performance office buildings (Wood 2012). This design choice is primarily attributed to its potential for reducing energy consumption due to HVAC systems (BRECSU 2000; Emmerich, Dols, and Axley 2001; Wood 2012) and higher user satisfaction (Mendell et al. 1996; Bauman 1999; Seppanen and Fisk 2002; Huizenga et al. 2006; Brager and Baker 2008; Mendell and Mirer 2009; de Dear 2010, 2011; Frontczak et al. 2012). Occupants of naturally ventilated buildings have been shown to be substantially more satisfied in terms of thermal comfort and indoor air quality (IAQ), when compared to occupants of mechanically ventilated or allair buildings. Research has demonstrated that satisfaction resulted from lower symptoms connected to the sick building syndrome (Mendell et al. 1996; Seppanen and 
Fisk 2002; Mendell and Mirer 2009) and from higher environmental control (Bauman 1999; Huizenga et al. 2006; Brager and Baker 2008; de Dear 2010, 2011; Frontczak et al. 2012). Mechanically ventilated and all-air systems can also ensure healthy and satisfactory environments, provided they are regularly maintained, although their operation requires substantially higher energy and economic costs (Mendell et al. 1996; Seppanen and Fisk 2002; Mendell and Mirer 2009).

Several established researchers (de Dear and Brager 1997, 1998; Humphreys and Nicol 1998; McCartney and Nicol 2002; Nicol and Humphreys 2002, 2004; Nicol and Pagliano 2007), who informed the ASHRAE Standard 55 (ASHRAE 2013) and the CEN EN 15251 (CEN 2007), showed that occupants may accept a wider range of temperatures in naturally ventilated buildings. This is explained by a wider psychological adaptation due to a higher degree of environmental control. The broader scope of acceptable indoor temperatures may further reduce the cooling costs (McGilligan, Natarajan, and Nikolopoulou 2011).

The effectiveness of natural ventilation is a function of many parameters and constraints. The CIBSE Good Practice Guide 237 (CIBSE 1998) outlines the design of naturally ventilated systems as an eight-step process: develop design requirements, plan airflow paths, identify building uses and features that might require special attention, determine ventilation requirements, estimate external driving pressures, select the types of ventilation devices, select the size of ventilation devices, and analyse the design. Emmerich, Stuart Dols, and Axley (2001) propose a design-oriented synthesis of the eight-step process: conceptual design (steps 1, 2, 3, and 4), design development (steps 5, 6, and 7), and design performance evaluation (step 8). McConahey (2008) outlined a top ten feasibility question list, to be reviewed as a starting point, if natural ventilation will be used as a primary cooling mechanism. 
The design of a natural ventilation system can broadly be summarised as a threestep iterative process (1-2-3, from the list below), where the constraints are addressed by answering the following three questions:

(1) Is the climate adaptable to natural ventilation?

Parameters/constraints: ambient temperature and humidity, air pollution, and acoustic pollution.

(2) Is the building designed for natural ventilation?

Parameters/constraints: heat gains, building geometry, envelope characteristics, ambient temperature, indoor free-running temperature, as well as the wind direction, velocity, and frequency (i.e. stack effect, wind effect).

(3) Does natural ventilation provide comfortable environments?

Parameters/constraints: indoor temperature and relative humidity, as well as indoor air and acoustic quality.

The conceptual design phase mostly addresses the first question, while the actual design of the ventilation strategy and system, and the following performance evaluation phase, mostly focus on the second and third questions. As already mentioned, it is an iterative process in common professional practice, where conceptual design esteems must be checked and eventually corrected on the basis of decisions made during the detailed design phase.

It is therefore fundamental to identify and use the proper methodology and tools, according to the design level challenged.

Several calculation methods for the stack effect and wind-driven ventilation are available, combined or not with energy simulation tools. Some simple methods may be easily implemented in electronic spreadsheets, such as the ones described in the CIBSE 
Application Manual AM10 (CIBSE 2005) or LoopDA, a natural ventilation design tool developed by the National Institute of Standards and Technology (Stuart Dols, Emmerich, and Polidoro 2012). The airflow networks implemented by some energy simulation tools guarantee more accurate results, although each environment (modelled as a zone) is still described by its average conditions (Gu 2007; Warren 2000). Using Computational Fluid Dynamics (CFD) enables accurately simulating the effect of wind, thermal stratification, and building geometry. However, simulations require a high calculation power (Nielsen et al. 2007). Physical models and in situ measurements may be even more expensive and time-consuming than CFD, although they may be quite useful for design optimisation (Etheridge and Sandberg 1996; Allard 1998; CIBSE 2005; Etheridge 2011).

All of these tools are very helpful during the detailed design of buildings, but they are not adaptable to the conceptual level, where a first approximation of the natural ventilation potential is required. The following analysis describes available tools and methodologies to analyse the climate at the conceptual design phase.

\section{2- Tools and methodologies for climate analysis}

Analyses to evaluate if a climate is adaptable for natural ventilation (and other passive strategies), or to contrast two different climates, are commonly performed by designers, although a shared methodology that includes comfort constraints is not yet available.

One of the first graphical tools to determine which combination of environmental conditions (dry bulb temperature (DBT), relative humidity (RH), air velocity, and radiation) would guarantee a comfortable indoor environment was introduced by Olgyay $(1953,1963)$ as the 'bioclimatic chart'. It has the RH on the horizontal and the DBT on the vertical axis, and the aerofoil shape in the middle 
represents the 'comfort zone', with winter and summer ranges indicated separately. Curves above the comfort zone show how air movement (in relation to humidity) can extend the upper limits, and lines below it show the radiation extension. The bioclimatic chart was drawn on the basis of the early comfort studies by the British Department of Scientific and Industrial Research, directed by H. M. Vernon and T. Bedford, similar studies by the Australian Commonwealth Experimental Building Station, and research results from S. F. Markham, C.E.P. Brooks, Hougton, Yaglou, and Drinker (Olgyay 1963). As pointed out by Olgyay, an exact criterion to evaluate thermal comfort did not exist at the time (or even today, if we exclude PMV for fully conditioned buildings). Therefore, the comfort zone refers to the literature review for the average human being. It is worth noting that $\mathrm{RH}$ comfort limits are set in the bioclimatic chart from $30 \%$ to $65 \%$ and that two extended areas are considered between $18 \%$ and $30 \%$ and between $65 \%$ and $78 \%$, but only for short periods in the absence of thermal stress. The effect of air velocity on comfort under high humidity levels (i.e. the vapour partial pressure between 15 and 23 mm of mercury) was calculated using the Carrier psychrometric chart based on research from Paul Siple and the John B. Pierce Foundation at Yale University (Olgyay 1963).

New comfort indexes were introduced in the following years: the PMV and PPD (Fanger 1970) and the new effective temperature ET* and its standardised version, the SET (Gagge, Stolwijk and Nishi 1971; Rohles, Hayter and Milliken 1975; Gagge, Fobelets, Berglund 1986). In particular, the SET coincides with DBT at the 50\% RH curve. The slope of the SET lines indicates that the temperature tolerance is reduced at higher humidity levels, while higher temperatures are acceptable at lower humidity levels (Szokolay 2008). The SET thus combines the effect of temperature and humidity 
and can be plotted on the ASHRAE psychrometric chart, providing a better definition of the comfort zone.

The ASHRAE comfort zone is derived from the ASHVE chart, which correlated temperature, humidity, and comfort response and was first published in the ASHVE guide in 1924 (Janssen 1999). The ASHRAE comfort zone included in the first publication of the ASHRAE Standard 55 in 1974, and in the following revised version from 1981, set a maximum limit of $12 \mathrm{~g} / \mathrm{kg}$ as a humidity ratio and a minimum limit of $4 \mathrm{~g} / \mathrm{kg}$ (Berglund 1998, Janssen 1999; Visitsak 2007). In the updated version from 1992, a RH maximum limit was set at $60 \%$, while the minimum limit of $4 \mathrm{~g} / \mathrm{kg}$ was maintained for the humidity ratio (Berglund 1998). In the following version from 1994, the maximum humidity limit was changed again, set as a maximum wet bulb temperature (WBT) of $18^{\circ} \mathrm{C}$ for winter $\left(1.0\right.$ clo) and $20^{\circ} \mathrm{C}$ for summer ( 0.5 clo) (Berglund 1998). This change was actually anticipated by the 1992 addendum to the standard (Fountain et al. 1999). In the 2004 revised version of the standard, the maximum limit of $12 \mathrm{~g} / \mathrm{kg}$ for the humidity ratio was reinstated, while the minimum limit was removed (i.e. no recommended lower limit). Moreover, it was the first international standard that included an optional method for determining acceptable thermal conditions (i.e. an operative temperature) in naturally conditioned spaces. The 2010 version of the standard, and the following 2013 version, introduced two further dashed areas in the chart: the first for a humidity ratio above $12 \mathrm{~g} / \mathrm{kg}$, which requires a computer model analysis, and the second for air speed above $0.2 \mathrm{~m} / \mathrm{s}$, to increase the upper operative temperature limit due to elevated air speed (Turner 2011; ASHRAE 2013).

The current version of the ASHRAE comfort zone for mechanically conditioned buildings and the adaptive comfort chart for naturally ventilated buildings are available 
through an interactive online tool developed by the Center for the Built Environment of the Berkeley University (Schiavon, Hoyt and Piccioli 2014).

The ASHRAE comfort zone is a design tool developed to graphically determine all of the possible comfortable combinations of indoor climate parameters (operative temperature, $\mathrm{RH}$, humidity ratio) for a given activity and clothing insulation. Since the comfort zone is plotted on a psychrometric chart, it also enables conducting a climatic analysis. If weather data is plotted on the same chart, it is possible to count the number of points (i.e. usually hours) for which the outdoor climatic conditions fall within the comfort zone. During these hours, it is possible to introduce outdoor air by means of natural ventilation without substantially affecting thermal comfort conditions. If cooling is required and outdoor weather conditions are favourable, natural ventilation may also improve thermal comfort conditions (in reality, its effectiveness depends on many more parameters including solar and internal heat gains).

Based on his own research and the work of others, Givoni observed that the ASHRAE comfort zone, which was intended for use in conditioned buildings, was inappropriate for buildings where passive strategies were adopted, especially in hot climates (Givoni 1969, 1998; Lomas et al. 2004). He also argued that Ogyay’s bioclimatic chart had several practical limitations and showed that it could lead to erroneous conclusions (Givoni 1969, 1998). To address these problems, he developed the Building Bio-Climatic Chart (BBCC). The BBCC is based on a building's expected indoor temperature resulting from passive conditioning strategies, instead of the outdoor temperatures, as in Olgyay’s chart (Givoni 1998), and it is drawn on a conventional psychrometric chart, as the ASHRAE comfort zone. The BBCC suggests boundaries for the climatic conditions with which various building design strategies, as well as passive and low-energy cooling systems, can provide comfortable indoor conditions (Givoni 
1998). The original comfort boundaries in the BBCC (Givoni 1969) were developed through practical research in Europe, the USA, and Israel, using experimental buildings of residential scale with low internal heat gains (Lomas et al. 2004). A revised version of the BBCC was later presented for hot developing countries (Givoni 1998). Givoni’s BBCC covers the following passive cooling strategies: daytime ventilation, high mass with or without nocturnal ventilation, direct evaporative cooling, and indirect evaporative cooling. It should be noted that Milne and Givoni considered the boundaries to be fuzzy and even ambiguous. This is indicated by the arrows that they frequently include on their chart (Visitsak 2007).

A practical graphics-based, free, and stand-alone computer programme is Climate Consultant, which integrates both Givoni’s BBCC and the ASHRAE Standard 55 comfort model (both adaptive and Fanger's). This tool enables the analysis of typical weather data and graphical representation, such as: a monthly diurnal average plot of dry and wet bulb temperatures, bar diagrams of direct and global radiation, sun shading charts, wind rose bars, etc.

By plotting ambient weather data on the psychrometric chart, and superimposing on it Givoni's BBCC, the tool calculates the number of points (i.e. hours) when outdoor conditions fall within the boundary comfort envelopes of the following options: comfort zone (according to ASHRAE models), sun shading of windows, high thermal mass with or without night ventilation, direct evaporative cooling, two-stage evaporative cooling, natural ventilation, fan-forced ventilation cooling, internal heat gain, passive solar direct gain and low or high thermal mass, wind protection of outdoor spaces, humidification only, heating and humidification, dehumidification only, as well as cooling and dehumidification. 
ArchiPak is another programme package that enables performing weather analysis on the basis of Givoni’s BBCC. Szokolay (2008) described the algorithms used by this tool to calculate the comfort envelopes of different passive strategies.

Ecotect Weather Tool is a flexible and interactive add-on for the Autodesk Ecotect software, which provides the user with visualisations of weather data that is imported into Ecotect. In the thermal comfort section, a comfort zone is overlaid on weather data plotted on the psychrometric chart. By changing the activity level of the occupants (from sedentary to heavy), the user can modify the comfort region's position, but the remaining parameters (clothing insulation, air speed, and mean radiant temperature) cannot be modified. The tool allows calculating how often the outdoor air temperature and humidity fall within the comfort zone boundaries, but it does not provide information related to the thermal comfort standard compliance. The weather tool also provides an analysis of passive design techniques including passive solar heating, thermal mass, night-purge ventilation, natural ventilation, direct evaporative cooling, and indirect evaporative cooling, such as in Givoni’s BBCC. The algorithms, which form the basis for determining the comfort zones and their extended boundaries due to passive strategies, are not publicly available and no references to standards are made (Schiavon, Hoyt and Piccioli 2014).

Other analysis methodologies that are available to assess the natural ventilation potential for buildings include various types of building modelling. Artmann, Manz, and Heiselberg (2007) proposed site-specific regression models to evaluate the climatic potential for night-time ventilation cooling based on the degree-hours method. Emmerich, Polidoro, and Axley (2011) developed an analysis method, based on a simplified thermal model of a commercial building, to evaluate the potential of a given location for direct ventilative cooling and night-time ventilative cooling. It neglects to 
account for conductive losses and assumes that these are typically small during warm periods, relative to internal gains for commercial buildings. The Climate Suitability Tool, which is freely available online, implements the outlined method (Axley 2001). Ghiaus and Allard (2006) proposed a calculation method based on the free-running temperature to obtain quick estimates of the potential energy savings for cooling through ventilation. The method may be used to interpret the results of building simulation software or of field measurements. Germano (2007) implemented a semiqualitative multicriteria analysis method to assess the natural ventilation potential of the Basel region.

The feasibility of using natural ventilation in a given climate depends primarily on the outdoor air quality, temperature, and humidity. The outdoor air quality is a function of the local orography and mesoclimate (mountains, hills, lakes, wind, etc.), local pollution levels, and policies promulgated to regulate them (Beattie, Longhurst, and Woodfield 2001; Williams 2004; Kanada et al. 2013). It is therefore difficult to evaluate, at a general level, if the outdoor air quality is good enough to promote natural ventilation, because it varies a lot with time (it mostly depends on the time when the analysis is performed). It is the designer's responsibility to obtain up-to-date measurements and information about local policies and future scenarios to evaluate whether natural ventilation is suitable in a certain area (acoustic pollution should be considered together with air quality). Advanced control algorithms that include an air quality analysis on the basis of local measurements are possible and have been developed (Germano 2007), but these are outside of this study's scope, because such data is hardly available. Outdoor temperature and humidity may instead be monitored and analysed with more confidence to establish how much the outdoor climate can foster natural ventilation (although the climate also varies with time, as its shifts are 
established over decades or centuries).

A summary of available tools is reported in Table 1, where a classification is proposed according to the design phase when a tool may prove useful.

Table 1. Summary of available tools for climatic analysis and natural ventilation, ranked according to the design phase when they apply.

\begin{tabular}{lc}
\hline Tool & Design phase \\
\hline Olgyay's bioclimatic chart & \\
Givoni's Building Bio-Climatic Chart & \\
ASHRAE thermal comfort chart & Conceptual design \\
Ecotect Weather tool & \\
Climate consultant & \\
ArchiPak & \\
Climate suitability tool & \\
Loop DA & \\
CIBSE Envelope flow models & \\
Contam & \\
Airflow networks included in energy simulation software & \\
CFD & \\
Physical models & \\
\hline
\end{tabular}

Givoni’s BBCC and Olgyay’s bioclimatic chart differ from the other analysis methods that were reviewed, because they do not rely on a specific building model and, in the case of natural ventilation, do not account for a specific ventilation strategy (e.g. cross, single side, stack-effect, wind driven, etc.). Lomas (Lomas et al. 2004) explained the limited applicability of Givoni’s BBCC, mostly because it is based on field measurements for a limited number of residential scale buildings; while Givoni himself (1969, 1998) showed the limits of Olgyay’s bioclimatic chart.

On the other hand, the boundary conditions of the optimal indoor operative temperature as a function of the outdoor temperature, which are reported by the ASHRAE Standard 55 and the CEN EN 15251 adaptive models for naturally ventilated buildings, are based on large international databases. These boundaries are not fixed but vary from month to month or day to day and apply to any building where natural 
ventilation is provided by giving the occupants some control through operable windows. The ASHRAE adaptive model originally combined the effects of temperature and water vapour into the effective temperature index $\left(\mathrm{ET}^{*}\right)$ that accounts for the effect of humidity. Nevertheless, this approach shed no light in the separate effect of humidity (Nicol 2004), although this has been shown to be important both for thermal comfort (at least at high temperatures) and especially for the IAQ (Givoni 1969; Berglund 1998; Fountain et al. 1999; Wyon et al. 2006). Moreover the equations adopted for the model were reworked when used for the standard and ET* was substituted with the mean monthly and then with the prevailing mean outdoor air temperature, which do not account for humidly.

This paper proposes a methodology to evaluate whether a climate is suitable for the use of natural ventilation and shows practical applications. It is intended for conceptual designs where quick calculations are necessary and a first approximation of the natural ventilation potential is required, irrespective of the ventilation strategy, as that is yet to be defined. It does not focus on a given technology and does not rely on simplified building models. In fact, it only relies on weather data and includes adaptive comfort models reported in the literature and a proposal of adaptive humidity constraints linked to the adaptive comfort temperature limits. The output of the analysis is a theoretical, yet realistic, maximum of the climatic potential that is achievable in a given climate, and it may be used by designers and clients as a benchmark to verify the following design steps when the natural ventilation strategy is designed and checked. The actual time when natural ventilation will be performed depends on: the envelope characteristics, the internal and solar heat gains, the control strategy, the occupants' behaviour, etc., and it typically is lower than the benchmark (i.e. the potential designated at the conceptual design phase). 
The methodology, connected metrics, and graphical representations may prove useful during the conceptual design phase to establish how far natural ventilation can be exploited, according to the local climate, and what active/passive technologies should be considered to compensate for the most critical periods. It may also be used to contrast different climates in terms of the natural ventilation potential.

\section{3-Background}

The first objective of a ventilation system is to provide occupants with clean air (i.e. air with a concentration of contaminants that is lower than in the occupied environment). If the air quality of the outdoor space is better than the indoor air quality, it is possible to naturally ventilate buildings (provided that no acoustical issue is detected). To avoid overheating, natural ventilation may only be used when the outdoor temperature is lower than or equal to the indoor one. If the ambient temperature is too cold, it may be necessary to preheat it before introducing the ventilated air into the occupied environment. Humidity also affects occupant well-being, therefore, natural ventilation is only possible when the ambient humidity ratio mixed with the indoor humidity ratio develops into an indoor relative humidity within the comfort range, which is usually considered between 30\% and 70\% (Givoni 1969; Berglund 1998; Fountain et al. 1999; ASHRAE 2009b). Humidity limits require maintaining acceptable thermal conditions, which are solely based on comfort considerations, including thermal sensation, skin wetness, skin dryness, and eye irritation (ISO 2005). The last version of the ASHRAE Standard 55 does not include a lower humidity limit, because it does not consider dry skin, mucus membrane irritation, dry eyes, and static electricity generation to be part of thermal comfort but rather of IAQ, which is outside of the standard's scope (Wyon et al. 2006; ASHRAE 2013). Nevertheless, when a natural ventilation system is designed, both IAQ and thermal comfort must be accounted for, and a RH range should be 
considered. In fact, non-thermal comfort factors, such as dry skin and mucus membrane irritation, may place limits on the acceptability of very low humidity environments (Wyon et al. 2006), and thermal discomfort places limits on the acceptability of very high humidity environments. The comfort zone's upper and lower limits are controversial and not clearly defined, which is evidenced by the evolution of the ASHRAE Standard 55, as outlined in previous sections. However, to calculate the natural ventilation climatic potential during the early conceptual design, the large, yet typical, $30 \%$ to $70 \% \mathrm{RH}$ range is a practical solution that is based on the available scientific literature.

Natural ventilation may be used for cooling purposes if the ambient air quality is good and the temperature and humidly are within an adequate range. Several technical solutions are possible: free-running (direct cooling of the occupied space), night-time cooling, activation of thermal mass, ventilation through a buffering space (double skin facades, atrium buildings, etc.).

The following analysis is not concerned with air quality and presumes that the outdoor air quality is suitable for natural ventilation; the methodology is not relevant if this condition is not met.

\section{4-Methods}

This work offers a methodology that establishes to what extent a climate shows favourable conditions for natural ventilation: it is an analysis based on the climate, not on the building. The Climatic Potential for Natural Ventilation (CPNV) is therefore an index that precedes any technological decision. The CPNV is defined as the number of hours in a year when natural ventilation could be performed, divided by the total number of hours in a year: 


$$
C P N V=\frac{\sum_{i=1}^{n} h_{N V, i}}{h_{t o t}}
$$

where $h_{N V, i}$ is the $i$-th hour when natural ventilation is possible and $h_{t o t}$ is the total number of hours in a year.

The analysis is based on a climatic database and constraints for indoor temperature and humidity. The CPNV is an ideal value that may be considered as a benchmark. It can measure the number of hours when natural ventilation is effectively exploited in a building, and this value will change every year. The more optimally a technology or a combination of technologies perform, the closer the effective hours of natural ventilation will be to the CPNV. The proposed index is an average value, since the CPNV is evaluated on the basis of a test reference year (TRY). This is normal and does not reduce the effectiveness of the proposed methodology to estimate the climatic potential for natural ventilation, which is by definition an average (or typical) value, because it is based on average climatic data (i.e. TRY). This same issue is also faced by energy simulations (Fabrizio et al. 2012).

The following is an analysis of weather data, and no information about the building is given (e.g. geometry, internal loads, etc.). The CPNV may be used to compare how much natural ventilation can be utilised in different climates or it can be used as a benchmark for designers to learn how far natural ventilation may be exploited in a given climate and avoid aiming at unrealistic targets.

\section{1-Boundary conditions}

Two thresholds are set to determine if the selected location allows for natural ventilation at a particular time of year. The ambient temperature (tout) must be within the comfort range established for the fluctuations of the indoor temperature and the ambient 
humidity ratio (Wout) must be within the comfort range established for the fluctuations of the indoor humidity ratio, as follow:

$$
\begin{gathered}
t_{i n, l} \leq t_{\text {out }} \leq t_{i n, u} \\
W_{i n, l} \leq W_{\text {out }} \leq W_{i n, u}
\end{gathered}
$$

where $t$ is the temperature and $W$ is the humidity ratio.

Two existing standards include an adaptive comfort model, which is useful for calculating the free-running comfort temperature ( $\left.\mathrm{t}_{\mathrm{comf}}\right)$ and its upper and lower limits: the ASHRAE Standard 55 and the CEN EN 15251. According to the standards, these models cannot be applied to mixed-mode buildings or buildings where some amount of mechanical cooling is used.

The ASHRAE 55 originally set the comfort temperature as a function of the mean monthly outdoor dry bulb temperature and now of the prevailing mean outdoor air temperature, while the CEN EN 15251 sets it as a function of the outdoor running mean temperature, i.e. the exponentially weighted running mean of the daily mean external dry bulb temperature. The two temperatures are similar but not the same.

For the sake of simplicity, the original ASHARE model where the comfort temperature is set as a function of the mean monthly outdoor dry bulb temperature was selected for the following calculation examples.

The upper limit for the indoor temperature $\left(t_{i n, u}\right)$ in the CPNV calculation may be set as equal to the one calculated when applying the ASHRAE procedure, choosing between $90 \%$ or $80 \%$ of satisfied occupants:

$$
\begin{aligned}
& t_{\text {in,u }}=t_{\text {comf }}+2.5 \quad(90 \% \text { satisfied }) \\
& t_{\text {in,u }}=t_{\text {comf }}+3.5 \quad(80 \% \text { satisfied })
\end{aligned}
$$




$$
t_{c o m f}=17.8+0.31 \cdot t_{d b}
$$

where $t_{d b}$ is the mean monthly outdoor dry bulb temperature (or the prevailing mean outdoor air temperature in the last version of the standard).

The lower limit $\left(\mathrm{t}_{\mathrm{in}, \mathrm{l}}\right)$ may also be set as equal to the lower limit that is calculated when the ASHRAE procedure is applied:

$$
\begin{aligned}
& t_{\text {in,l },}=t_{\text {comf }}-2.5 \quad(90 \% \text { satisfied }) \\
& t_{\text {in,l }}=t_{\text {comf }}-3.5 \quad(80 \% \text { satisfied })
\end{aligned}
$$

If natural ventilation is to be used for cooling purposes, it is advisable (and in accordance with professional practice) to shift down tin,l, compared to the value calculated by equations (7) and (8). Bourgeios, Potvin, and Haghigat (2000) suggest a lower limit of $12^{\circ} \mathrm{C}$ for natural daytime ventilation, which is similar to the lower limit of $10^{\circ} \mathrm{C}$ reported by the author on the basis of his practical design experience. A lower limit of $10^{\circ} \mathrm{C}$ to $12^{\circ} \mathrm{C}$ may be considered effective to contrast moderate heat gains. Lower values are not suggested to avoid thermal discomfort for occupants close to the ventilation openings, although lower temperatures may be used for night-time cooling when the building is unoccupied, or when using high-induction vents. Emmerich, Polidoro, and Axley (2011) suggest using the dew point temperature (DPT) to avoid surface moisture condensation. In Givoni’s BBCC and subsequent elaborations, a lower limit of $20^{\circ} \mathrm{C}$ is reported for air speed about $2 \mathrm{~m} / \mathrm{s}$, and a lower limit of $18^{\circ} \mathrm{C}$ for still air. Szokolay (2008) proposes calculating the lower limit by applying equation (7) and assuming it as the value of SET at 50\% RH. SET values should then be calculated for every DBT and humidity ratio combination. This may work for graphical representation, as suggested by Szokolay, but it may have drawbacks for analytical calculations at the conceptual design phase. 
The final value of the lower limit $\left(\mathrm{t}_{\mathrm{in}, \mathrm{l}}\right)$ may be set by designers according to their experience and intent. Table 2 reports some values found in the literature.

Table 2. Literature values for natural ventilation minimum supply temperature.

\begin{tabular}{|c|c|c|c|}
\hline$t_{\text {in, }, 1}$ & Reference & Approach & Comments \\
\hline $\begin{array}{l}t_{i n, l}=t_{c o m f}-2.5 \\
t_{i n, l}=t_{c o m f}-3.5\end{array}$ & $\begin{array}{l}\text { ASHARE 55; EN } \\
15251\end{array}$ & Conservative & $\begin{array}{l}\text { It does not account for higher } \\
\text { cooling potential usually } \\
\text { achievable, but it should } \\
\text { guarantee a low draught risk. }\end{array}$ \\
\hline 18 to $20^{\circ} \mathrm{C}$ & $\begin{array}{l}\text { Givoni 1969; } \\
1998\end{array}$ & Moderate & $\begin{array}{l}\text { It does not account for higher } \\
\text { cooling potential usually } \\
\text { achievable, but it should } \\
\text { guarantee a low draught risk. }\end{array}$ \\
\hline $12^{\circ} \mathrm{C}$ & $\begin{array}{l}\text { Bourgeois, } \\
\text { Potvin and } \\
\text { Haghighat } 2000\end{array}$ & $\begin{array}{l}\text { Typical } \\
\text { design } \\
\text { practice }\end{array}$ & $\begin{array}{l}\text { It may contrast moderate } \\
\text { internal heat gains, but draught } \\
\text { risk should be checked. }\end{array}$ \\
\hline $\begin{array}{l}t_{\text {in,l }}=t_{\text {dew }} \\
\text { (night-time } \\
\text { ventilation) }\end{array}$ & $\begin{array}{l}\text { Emmerich, } \\
\text { Polidoro, and } \\
\text { Axley } 2011 \\
\end{array}$ & $\begin{array}{l}\text { Typical } \\
\text { design } \\
\text { practice }\end{array}$ & $\begin{array}{l}\text { It should help avoiding surface } \\
\text { condensation. }\end{array}$ \\
\hline
\end{tabular}

Once the temperature thresholds are set, the humidity ratio thresholds can be calculated as a function of the two temperatures and relative humidity $(\mathrm{RH})$, as follows (ASHRAE 2009a):

$$
\begin{gathered}
W=0.621945 \cdot \frac{p_{w s} \cdot R H}{p-\left(p_{w s} \cdot R H\right)} \\
p_{w s}=f(t)
\end{gathered}
$$

As already mentioned, a 30\% to $70 \% \mathrm{RH}$ comfort range is usually assumed to guarantee both thermal and IAQ comfortable conditions (Givoni 1969; Berglund 1998; Fountain et al. 1999; Wayon et al. 2006; ASHRAE 2009b). Nevertheless, the relative humidity is not in itself a good indicator to verify whether outdoor air conditions are advantageous for using natural ventilation. Relative humidity is expressed as:

$$
R H=\frac{p_{w}}{p_{w s}}
$$

where $p_{w}$ is the partial pressure of vapour and $p_{w s}$ is the partial pressure of vapour under saturation conditions. 
Since $p_{w s}$ is a function of the air temperature, as equation (10) shows, RH is also a function of it. When the outdoor air enters a room and mixes with indoor air, the resulting $\mathrm{RH}$ value will be a function of the resulting indoor temperature even if the indoor and outdoor humidity ratios were the same.

If the humidity ratio (W) is instead used as an indicator, including two comfort thresholds of $30 \% \mathrm{RH}$ and $70 \% \mathrm{RH}$ in its evaluation, it is possible to calculate a lower and an upper limit for $\mathrm{W}$, such that when the ventilated air moves into the indoor environment up to the upper or lower temperature limit, the resulting $\mathrm{RH}$ value will always be inside the comfort range of $30 \%$ to $70 \% \mathrm{RH}$. The hypothesis behind this calculation is that the internal generation of moisture is low or negligible, and it is in accordance with the definition of the CPNV as a maximum ideal value or benchmark.

The upper limit for the humidity ratio $\left(\mathrm{W}_{\mathrm{in}, \mathrm{u}}\right)$ may be calculated for $\mathrm{RH}=70 \%$ and tin,u:

$$
\begin{gathered}
W_{i n, u}=0.621945 \cdot \frac{p_{w s} \cdot 0.7}{p-\left(p_{w s} \cdot 0.7\right)} \\
p_{w s}=f\left(t_{i n, u}\right)
\end{gathered}
$$

while the lower limit $\left(\mathrm{W}_{\mathrm{in}, \mathrm{l}}\right)$ may be calculated for $\mathrm{RH}=30 \%$ and $\mathrm{tin}_{\mathrm{in}, \mathrm{l}}$ :

$$
\begin{gathered}
W_{i n, l}=0.621945 \cdot \frac{p_{w s} \cdot 0.3}{p-\left(p_{w s} \cdot 0.3\right)} \\
p_{w s}=f\left(t_{i n, l}\right)
\end{gathered}
$$

To account for a higher internal moisture generation, the upper limit may be reduced by calculating it as a function of the lower temperature limit, as follow:

$$
\begin{gathered}
W_{i n, u}=0.621945 \cdot \frac{p_{w s} \cdot 0.7}{p-\left(p_{w s} \cdot 0.7\right)} \\
p_{w s}=f\left(t_{i n, l}\right)
\end{gathered}
$$

The approximations or hypotheses for the proposed methodology are as follows: 
(1) The indoor mean radiant temperature and dry bulb temperature are assumed to be equal. Therefore, the upper and lower limits ( $t_{\text {in,u }}$ and $\left.t_{\text {in, }, l}\right)$, which refer to the operative temperature according to the standards, may also be applied to DBT.

(2) Internal and solar heat gains are considered to be moderate, because the CPNV is considered to be a maximum benchmark for the given climate.

(3) The humidity generation in the indoor environment is considered to be low or negligible, because the CPNV is considered to be a maximum benchmark for the given climate.

If higher than moderate heat gains and/or internal humidity generation are considered, the analysis should be run reducing the upper limits for temperature and/or humidity. However, the method does not apply for buildings with very high heat gains or internal humidity generation.

\section{2-CPNV calculation}

Once the boundary conditions are fixed, two sets may be calculated. The A set is populated by the hours during which the ambient temperature (tout) is within the established range (Eq. 2); the B set is populated by the hours during which the ambient humidity ratio ( $\mathrm{W}_{\text {out}}$ ) is within the established range (Eq. 3).

The CPNV may be calculated as the intersection of set A and B:

$$
C P N V=A \cap B
$$

Eight further sets may be calculated to represent the number of hours when natural ventilation cannot be exploited, because it is: too hot, too cold, too dry, too humid, or any combination of these conditions (Figure 1). These are metrics of exceedance (Borgeson and Brager 2011), which can be both represented in a graphical way by heat maps or gathered in tables, where the number of hours of exceedance is 
counted adopting or not some weighting factors, such as the ones reported in CEN EN 15251.



Figure 1. Time of year subdivided in 9 areas according to temperature and humidity ratio thresholds.

\section{5-Calculation example}

A calculation example is provided to show the effectiveness of the proposed methodology. The analysis was made for London, utilising the International Weather for Energy Calculation (IWEC) database of climatic data.

The comfort temperature was calculated according to the ASHRAE 55 adaptive comfort model, as indicated in section four. The lower limit for the supply temperature was set at $10^{\circ} \mathrm{C}$. The relative humidity comfort range was assumed to be between $30 \%$ and $70 \%$, in accordance with the literature.

The monthly boundary conditions are reported in Table 3, along with the ASHREA 55 comfort ranges, RH ranges, supply air acceptable conditions, and CPNV. The CPNV may also be represented by means of a histogram (Figure 2) where the daytime and night-time values may be separated (e.g. daytime: 8 AM to 7 PM, nighttime: 8 PM to 7 AM). 
Table 3. Boundary condition and CPNV for the climate in London.

Indoor Boundary Conditions

\begin{tabular}{lccccccccc}
\hline & $\mathrm{t}_{\mathrm{I}}$ & $\mathrm{t}_{\mathrm{u}}$ & $\mathrm{RH}_{\mathrm{I}}$ & $\mathrm{RH}_{\mathrm{u}}$ & $\mathrm{t}_{\mathrm{in}, \mathrm{I}}$ & $\mathrm{t}_{\mathrm{in}, \mathrm{u}}$ & $\mathrm{W}_{\mathrm{in}, \mathrm{I}}$ & $\mathrm{W}_{\mathrm{in}, \mathrm{u}}$ & $\mathrm{CPNV}$ \\
& ${ }^{\circ} \mathrm{C}$ & ${ }^{\circ} \mathrm{C}$ & $\%$ & $\%$ & ${ }^{\circ} \mathrm{C}$ & ${ }^{\circ} \mathrm{C}$ & $\mathrm{g} / \mathrm{kg}$ & $\mathrm{g} / \mathrm{kg}$ & - \\
January & 16.7 & 21.7 & 30 & 70 & 10.0 & 21.7 & 3.50 & 8.23 & \\
February & 16.5 & 21.5 & 30 & 70 & 10.0 & 21.5 & 3.47 & 8.16 & \\
March & 17.4 & 22.4 & 30 & 70 & 10.0 & 22.4 & 3.67 & 8.64 & \\
April & 17.9 & 22.9 & 30 & 70 & 10.0 & 22.9 & 3.78 & 8.90 & \\
May & 19.2 & 24.2 & 30 & 70 & 10.0 & 24.2 & 4.10 & 9.66 & \\
June & 20.1 & 25.1 & 30 & 70 & 10.0 & 25.1 & 4.34 & 10.23 & \\
July & 20.7 & 25.7 & 30 & 70 & 10.0 & 25.7 & 4.51 & 10.62 & 0.47 \\
August & 20.5 & 25.5 & 30 & 70 & 10.0 & 25.5 & 4.46 & 10.50 & \\
September & 19.6 & 24.6 & 30 & 70 & 10.0 & 24.6 & 4.21 & 9.92 & \\
October & 18.6 & 23.6 & 30 & 70 & 10.0 & 23.6 & 3.95 & 9.30 & \\
November & 17.7 & 22.7 & 30 & 70 & 10.0 & 22.7 & 3.75 & 8.81 & \\
December & 16.9 & 21.9 & 30 & 70 & 10.0 & 21.9 & 3.55 & 8.35 & \\
\hline & & & & & & & & & \\
\end{tabular}

The analysis matrix may also be represented by heat maps, where the nine sets mentioned in section 4.2 can be graphically highlighted. Figure 3 reports the heat map of the average hourly weekly conditions; alternatively, hourly daily data can be plotted.

The CPNV, which was calculated using the methodology above, should be assumed to be a benchmark for the following design steps. Once London’s CPNV was established at 0.47 (i.e. natural ventilation may ideally be used $47 \%$ of the time during a year), the designer should assess how much the building is able to exploit this potential. Unfavourable wind directions, urban obstructions, high or low internal gains, building geometry, window discharge coefficients, etc. will affect the building's ultimate performance, and the number of hours when natural ventilation is technically pursuable is typically lower than the CPNV. 


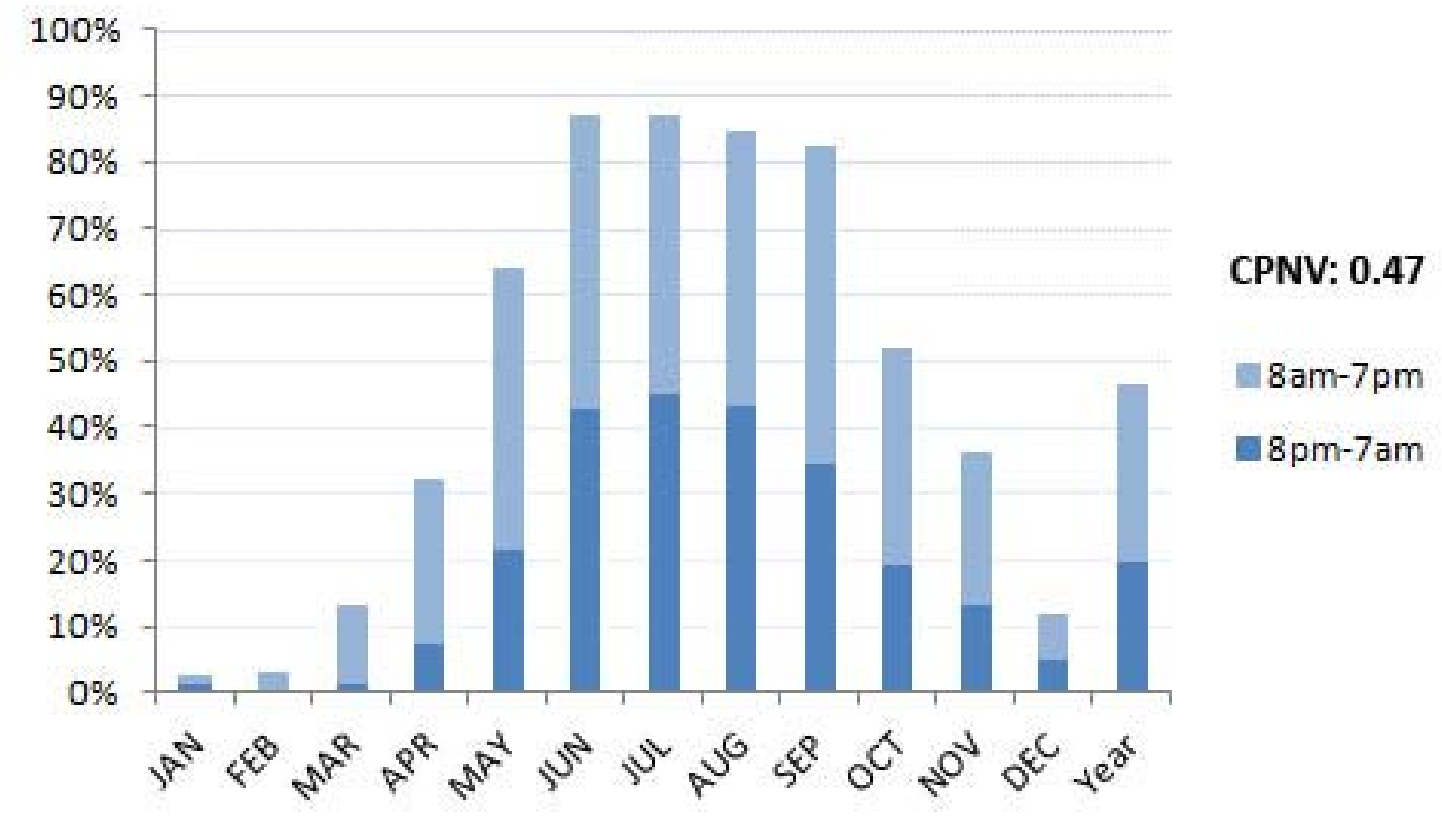

Figure 2. Percentage of time when natural ventilation is pursuable in London: monthly and yearly values.

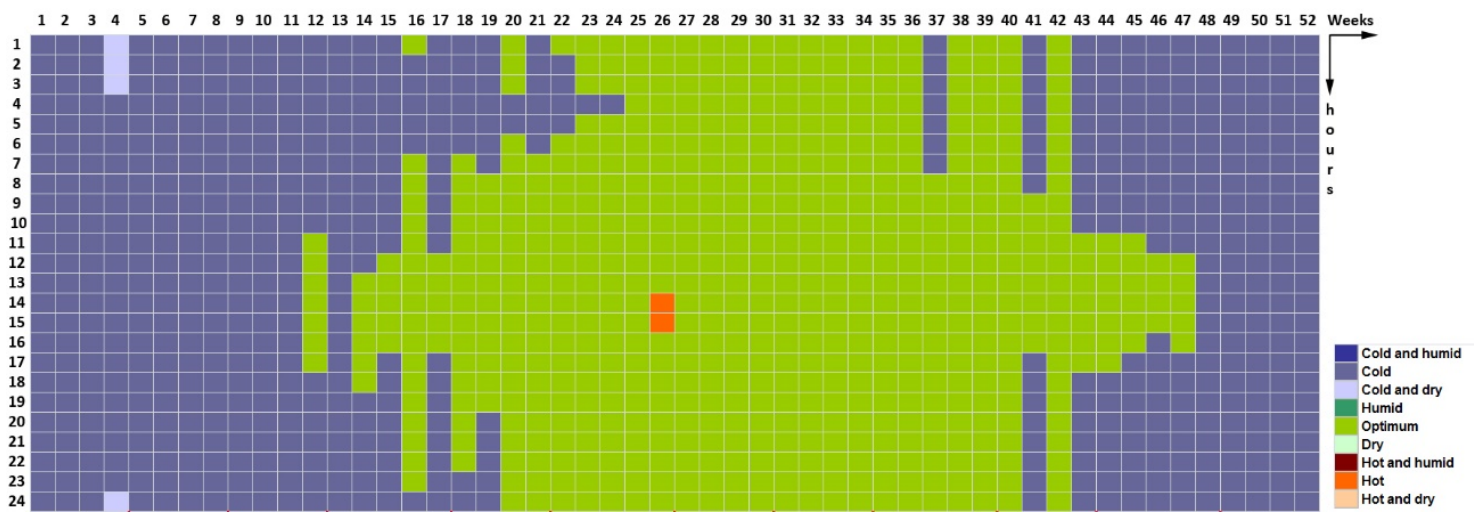

Figure 3. Heat maps representing the time of year when natural ventilation is pursuable in London. The week number is on the $x$-axis; the hours of the day are on the $y$-axis.

\section{6-Contrasting climates}

The methodology proposed in section four may also be used to compare different climates. Figure 4 shows a comparison of five reference cities, which were selected according to Mansy (2006) to represent five world climates (Ft. Smith was replaced by Oslo because of lacking weather data). 

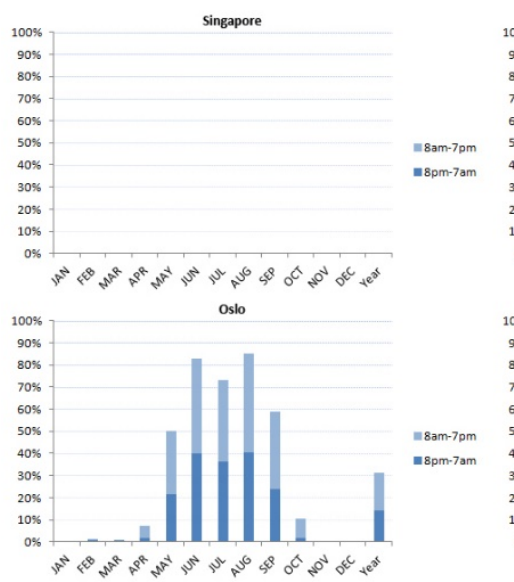
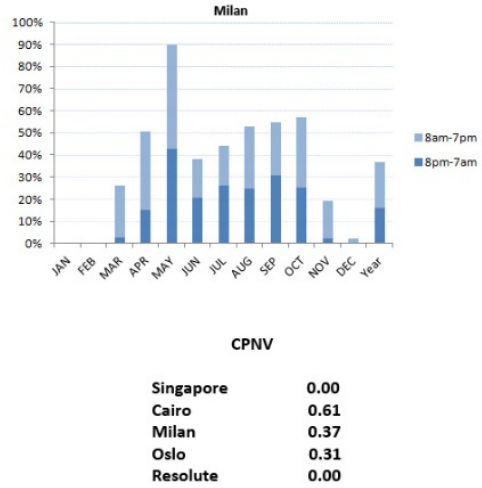

Figure 4. Comparison of 5 different climates represented by 5 cities: monthly distribution of natural ventilation potential, and yearly CPNV.

The analysis clearly reveals that in extreme climates, such as in Singapore and in Resolute, natural ventilation can hardly be utilised, even when an adaptive comfort approach is assumed. Nevertheless, a substantial difference exists between the two climates. In fact, if we consider only temperatures and do not perform the data screening based on the humidity ratio (Eq. 3), the CPNV for Singapore would be 0.73, while the one in Resolute would stay at 0.00 . The main issue in Singapore is humidity, while it is temperature in Resolute. Heat maps are useful to visually understand this. In Singapore, humidity is the main issue during the night-time for the entire year, while the climate is too hot and humid during the central daytime hours to perform natural ventilation (Figure 5). In Resolute, the climate is always cold and dry, apart from the time between weeks 24 and 36 (i.e. between June and September), when it is just too cold for natural ventilation (Figure 6). No substantial difference is noticed between the night and day.

If the analysis did not account for humidity, a potential overestimation would be made for hot and humid climates. An overestimation of 18\% in Cairo and 16\% in Milan would be made. In Oslo, the overestimation would be limited to 6\% (Table 4). 


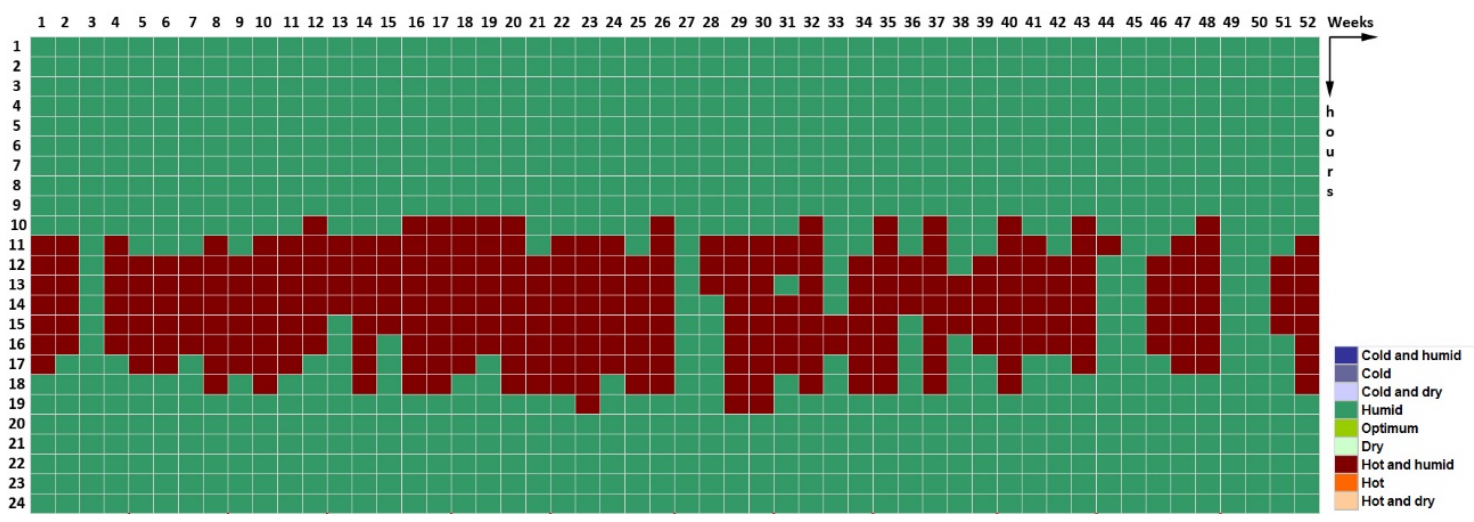

Figure 5. Heat map of the climate in Singapore showing relevant humidity issues.

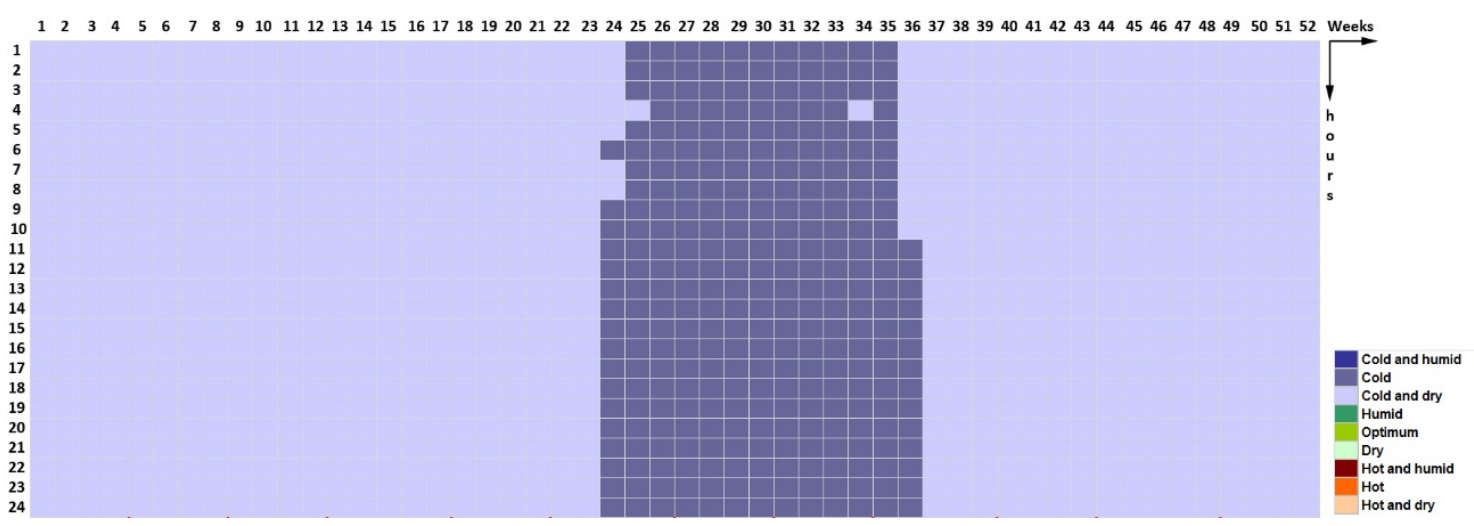

Figure 6. Heat map of the climate in Resolute showing relevant temperature issues, but no limitation depending on humidity.

Moreover, it is important to note that Milan and Oslo have a similar CPNV, although temperatures in Milan are much milder. The problem in Milan is the humidity, which substantially reduces the number of hours enabling natural ventilation.

Milan's heat map, reported in Figure 7, shows that the climate is too cold and sometimes even too dry to use natural ventilation during a large part of the winter, while natural ventilation is possible during the day in the spring. Between May and June and in September, weather conditions are good both during the day and night, while it is typically hot or hot and humid during the day and too humid during the night in the central months of summer. Figure 8 reflects data from Oslo where cold and sometimes dry weather is registered during the winter, as well as in much of the spring and autumn, while the entire summer time is very good for natural ventilation during the day and 
night. In Cairo, weeks 15 to 43 are too hot during the day, and it is too humid at nighttime between weeks 25 to 42 (Figure 9). But the climate is optimal for natural ventilation between weeks 1 and 14 and between weeks 46 and 52 .

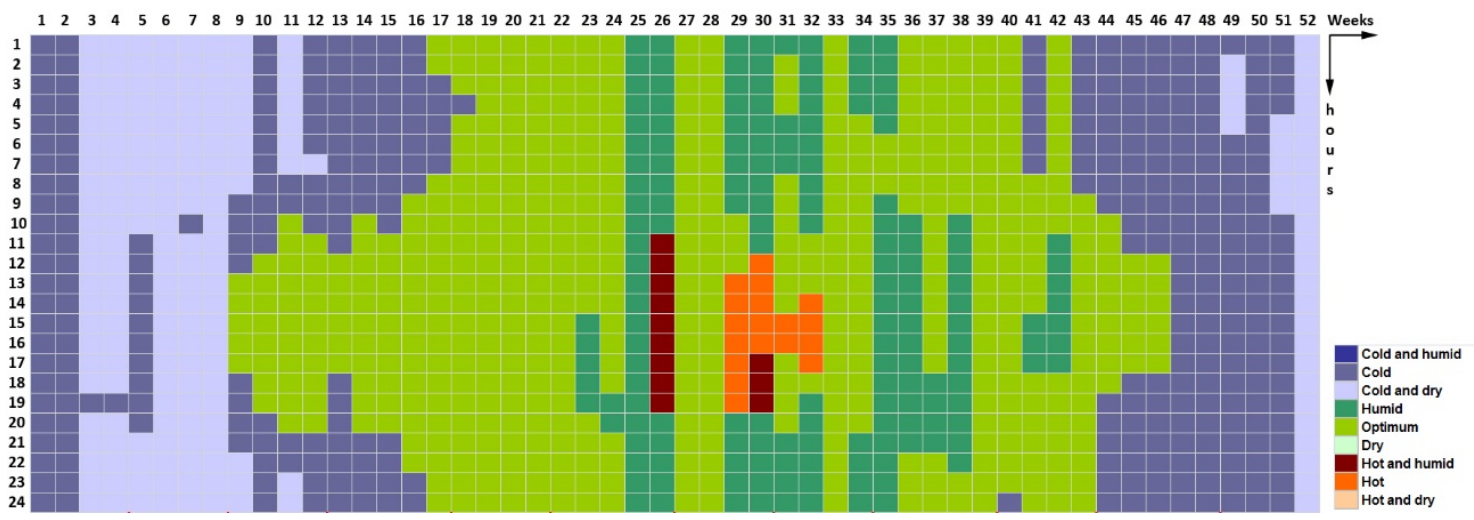

Figure 7. Heat map of the climate in Milan showing relevant humidity issues during the central months of the year and temperature limitations during winter.

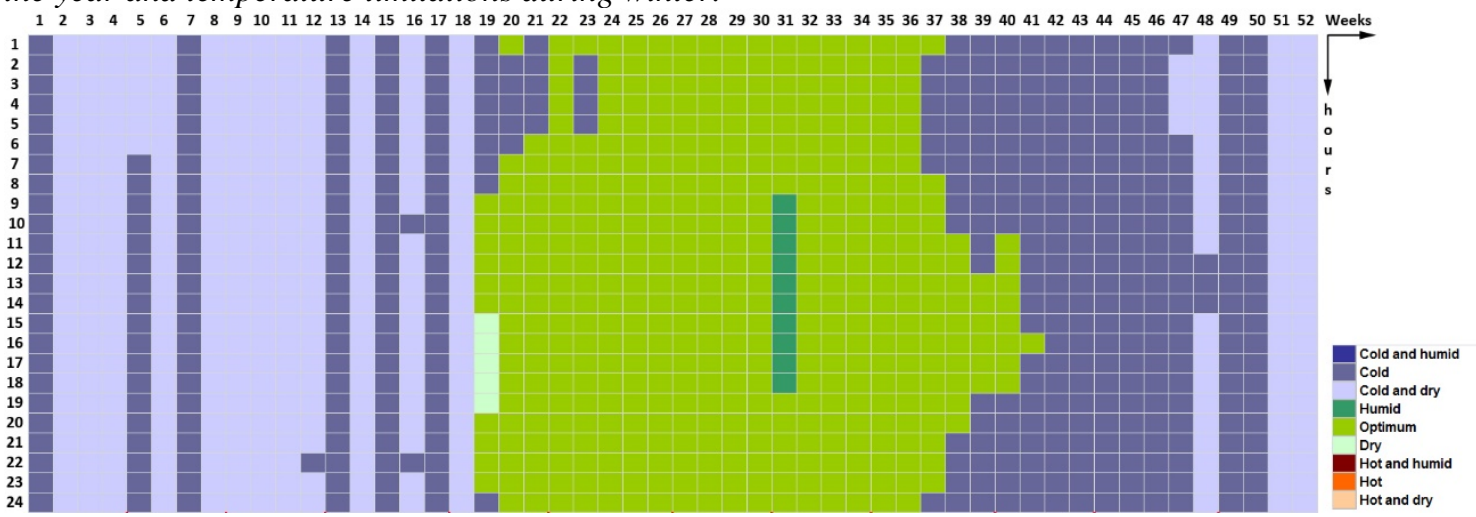

Figure 8. Heat map of the climate in Oslo showing temperature limitations during winter, but optimal condition for natural ventilation during the central months of the year.



Figure 9. Heat map of the climate in Cairo showing temperature limitations during the central hours of summer and humidity limitations during the night-time.

These results are in accordance with Givoni’s (1969) observations that the ambient temperature range aptitude is inversely related to the ambient vapour pressure. 
Under dry weather conditions, a high temperature range is reported during the night and day and therefore also a high CPNV, and vice versa in humid climates.

The results plotted in heat maps may be also gathered in a synthetic table, reporting exceedance metrics such as the number of hours or the percentage of time when natural ventilation cannot be performed (Table 4).

Table 4. Exceedance metrics in the 5 selected reference cities.

\begin{tabular}{lccccc}
\hline & Singapore & Cairo & Milan & Oslo & Resolute \\
\hline Cold and humid & $0 \%$ & $0 \%$ & $0 \%$ & $0 \%$ & $0 \%$ \\
Cold & $0 \%$ & $1 \%$ & $26 \%$ & $33 \%$ & $22 \%$ \\
Cold and dry & $0 \%$ & $0 \%$ & $17 \%$ & $30 \%$ & $78 \%$ \\
Humid & $73 \%$ & $16 \%$ & $15 \%$ & $3 \%$ & $0 \%$ \\
Optimum (CPNV) & $0 \%$ & $61 \%$ & $37 \%$ & $31 \%$ & $0 \%$ \\
Dry & $0 \%$ & $2 \%$ & $2 \%$ & $3 \%$ & $0 \%$ \\
Hot and humid & $27 \%$ & $5 \%$ & $2 \%$ & $0 \%$ & $0 \%$ \\
Hot & $0 \%$ & $14 \%$ & $1 \%$ & $0 \%$ & $0 \%$ \\
Hot and dry & $0 \%$ & $1 \%$ & $0 \%$ & $0 \%$ & $0 \%$ \\
\hline
\end{tabular}

A further example shows how important the humidity constraints are in evaluating the CPNV, even when considering cities in the same climatic zone, thus with similar climatic constraints. Data from six different Italian cities (Ancona, Florence, Genoa, Rome, Pescara, and Pisa) in the same climatic zone, according to Italian legislation, are analysed. Results reported in Table 5 show that the CPNV would be overestimated in Genoa and Rome by $29 \%$ and $31 \%$, respectively, if humidity constraints were not applied. The overestimation would be around 20\% in Ancona, Pescara, and Pisa. In Florence, the overestimation would be limited to $13 \%$.

Table 5. CPNV of 6 Italian cities in the same climatic zone, calculated with and without humidity constraints.

\begin{tabular}{lccccc}
\hline & HHD & $\begin{array}{c}\text { Altitude } \\
(\mathbf{m})\end{array}$ & CPNV & $\begin{array}{c}\text { cpnv } \\
\text { (only t) }\end{array}$ & DCPNV \\
\hline Ancona & 1688 & 16 & 0.48 & 0.68 & $20 \%$ \\
Firenze & 1821 & 50 & 0.50 & 0.63 & $13 \%$ \\
Genova & 1435 & 39 & 0.54 & 0.82 & $29 \%$ \\
Pescara & 1718 & 4 & 0.45 & 0.65 & $19 \%$ \\
Pisa & 1694 & 4 & 0.48 & 0.68 & $20 \%$ \\
Roma & 1415 & 20 & 0.45 & 0.76 & $31 \%$ \\
\hline
\end{tabular}


Results from Table 5 show that the six cities have about the same CPNV, around 0.5. Nevertheless, bar graphs that separately show how often the humidity ratio and the temperature fall within the respective limiting range may be quite useful to understand the dynamics of each city (Figure 10).

In Genoa and Rome, the temperature results are generally better than in Florence, but the humidity level is much higher in the summer (thus showing lower bars in the graph) and this substantially reduces the CPNV in these two cities. Although temperatures fall within the limit range for much of the summer, humidity values are within the range for a very short time, which substantially reduces the final CPNV value. As reported in Table 5, Genoa and Rome show the highest difference between the CPNV calculated with or without humidity constraints (i.e. $29 \%$ and $31 \%$ )
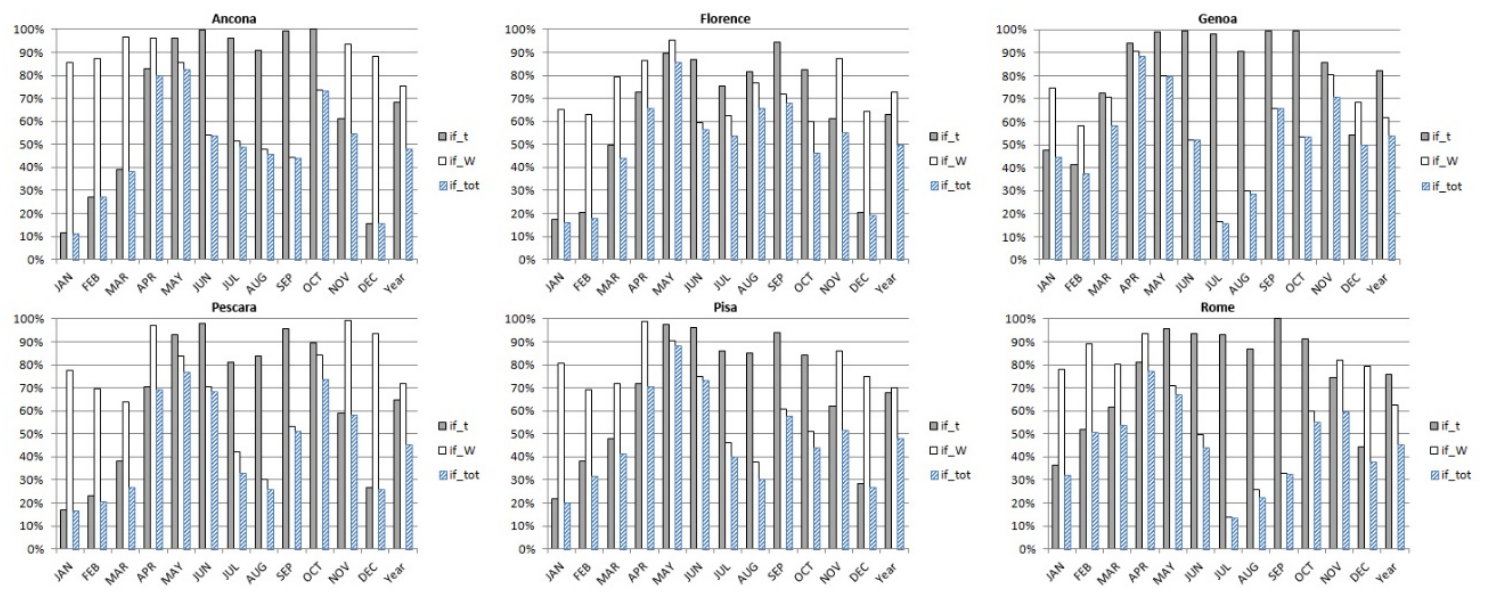

Figure 10. Comparison of 6 Italian cities in the same climatic area: monthly and yearly CPNV calculated according to temperature limits only (if_t), to humidity limits only (if_W), and combining both of the constraints (if_tot).

The results of this analysis are consistent with those reported by Givoni (1969) that there is interdependence between the vapour partial pressure and the ambient temperature range. Because the latter is connected to the ventilation potential, interdependence also exists between the vapour partial pressure and the CPNV. Figure 11 shows the profile of the average monthly value of the vapour partial pressure. It is 
evident that Rome and Genoa have higher values compared to the other cities - Genoa from April to August and Rome all year long. In contrast, Florence has the lowest values. In adherence with Givoni’s observation, there is a correlation between the reduction of the CPNV in Rome and Genoa during the summer months and the average monthly value of the vapour partial pressure. Figure 12 reports the profile of the average monthly value of the humidity ratio in the six reference cities. These profiles are similar to the ones reported in Figure 11; the humidity ratio and the vapour partial pressure are, in fact, functionally correlated. The humidity ratio therefore proves to be an important indicator to evaluate the climatic potential for natural ventilation.

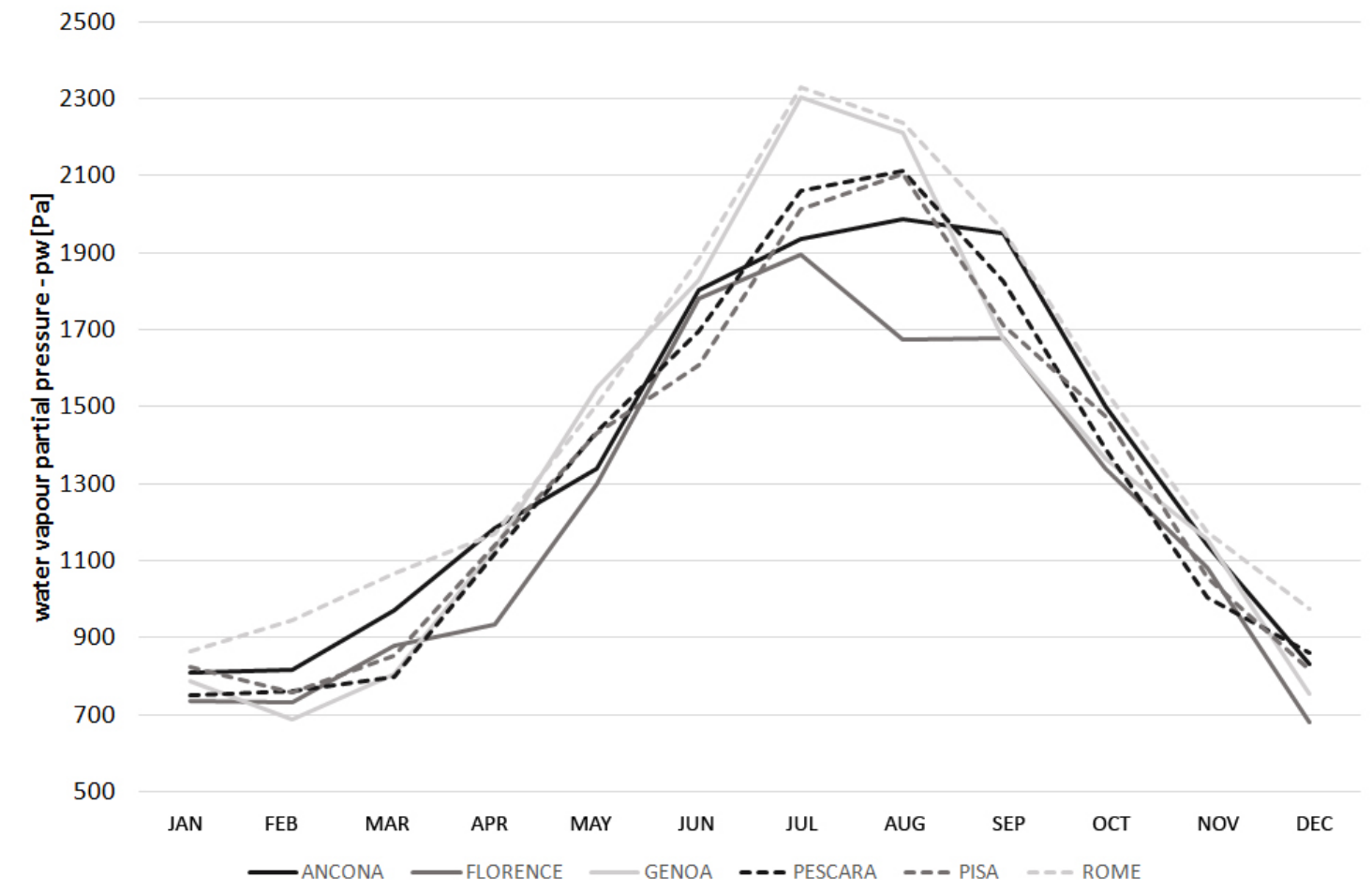

Figure 11. Profiles of the average monthly water vapour partial pressure in the 6 reference cities. 


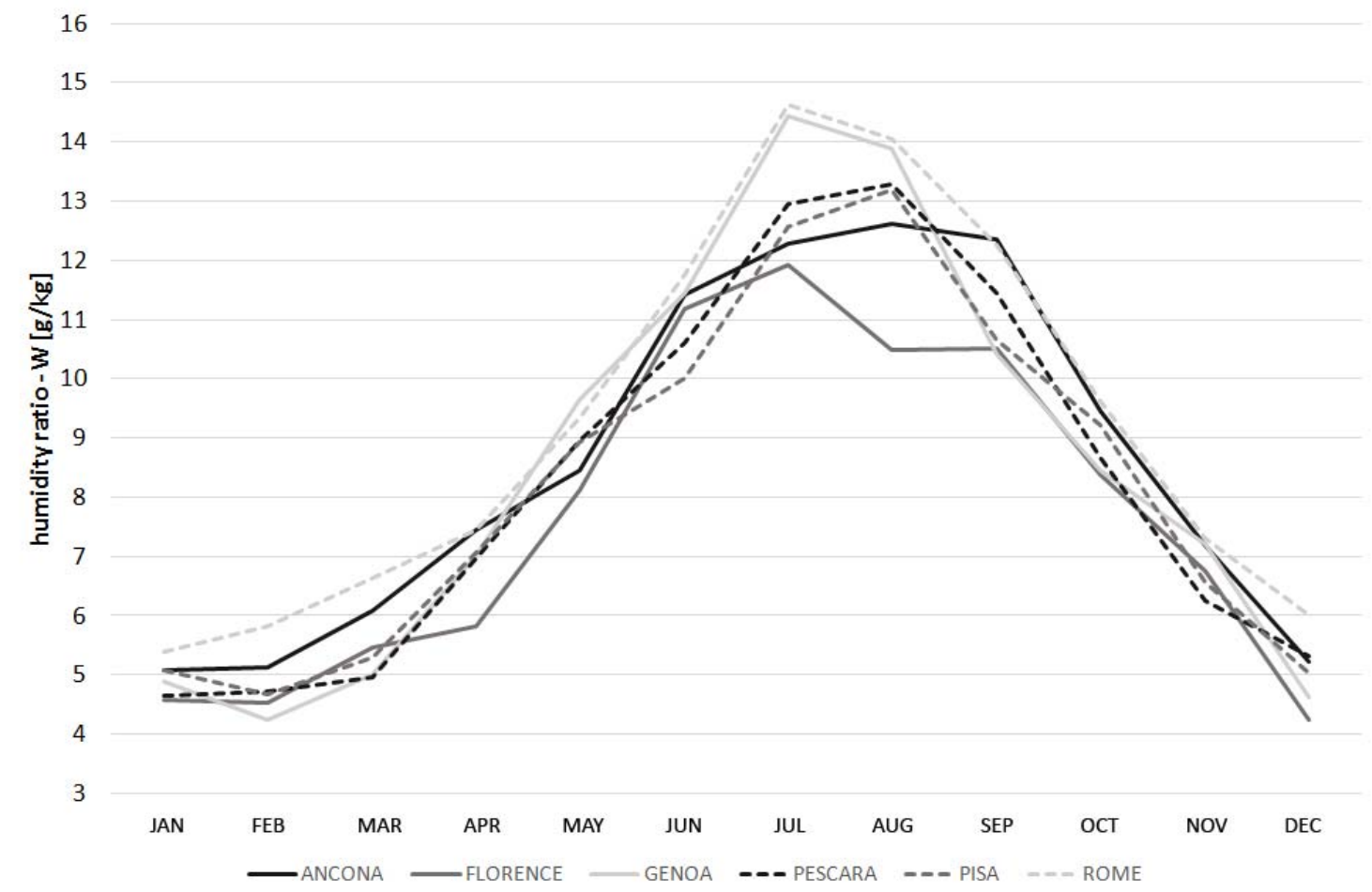

Figure 12. Profiles of the average monthly humidity ratio in the 6 reference cities.

\section{7-Results and Discussion}

A methodology to evaluate the Climatic Potential for Natural Ventilation (CPNV) of a given climate is proposed on the basis of adaptive comfort models (ASHRAE 55, EN CEN 15251) and humidity constraints.

This methodology may prove useful during the conceptual design stage of a building to define the maximum number of hours when natural ventilation could ideally be utilised in a given climate. Further analysis will be necessary in the following design phases to determine how long natural ventilation can be performed in the building, considering all of the technical constraints. The CPNV may therefore be used as a benchmark during the detailed design process of the natural ventilation strategy. The methodology may also be used to contrast different climates, in order to highlight where natural ventilation is more appropriate.

Two different analyses on eleven cities showed that the adaptive comfort model reported in the standards is not enough to evaluate the CPNV of a given climate. 
Humidity also plays a fundamental role and should be considered in the analysis. The methodology proposed in this paper includes humidity constraints using the humidity ratio as an indicator. Its upper and lower limits are calculated by assuming an indoor comfortable relative humidity range between $30 \%$ and $70 \%$, in accordance with the literature. This is a large range that allows for adaptation; nevertheless, it is possible to observe a wider adaptation to higher humidity levels in hot and humid climates (Givoni 1998; Nicol 2004). A more comprehensive adaptive model that includes humidity is therefore strongly needed.

\section{Nomenclature}

BBCC Building bio-climatic chart

CPNV Climatic potential for natural ventilation

DBR Dry bulb temperature $\quad{ }^{\circ} \mathrm{C}$

DPT Dew point temperature ${ }^{\circ} \mathrm{C}$

hNv Hour when natural ventilation is possible $\quad h$

$\mathrm{h}_{\text {tot }} \quad$ Total amount of hours in a year $\quad \mathrm{h}$

HDD Heating degree-day $\quad{ }^{\circ} \mathrm{C}$ HDD

MRT Mean radiant temperature $\quad{ }^{\circ} \mathrm{C}$

$\begin{array}{lll}\text { p Atmospheric pressure } & \mathrm{Pa}\end{array}$

pw $\quad$ Partial pressure of water vapour $\quad \mathrm{Pa}$

Pws $\quad$ Partial pressure of water vapour under saturation conditions $\quad \mathrm{Pa}$

$\begin{array}{lll}\mathrm{RH} & \text { Relative humidity }\end{array}$

SET Standard effective temperature $\quad{ }^{\circ} \mathrm{C}$

$\begin{array}{lll}\text { tcomf } & \text { Free-running comfort temperature } & { }^{\circ} \mathrm{C}\end{array}$

$\mathrm{t}_{\mathrm{db}} \quad$ Mean monthly outdoor dry bulb temperature $\quad{ }^{\circ} \mathrm{C}$ 


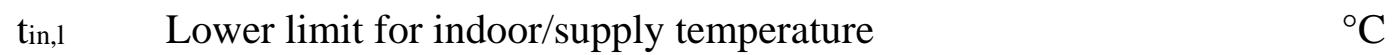

tin,u $\quad$ Upper limit for indoor/supply temperature $\quad{ }^{\circ} \mathrm{C}$

tout Ambient (or outdoor) temperature $\quad{ }^{\circ} \mathrm{C}$

Win,l Lower limit for indoor/supply humidity ratio g/kg

Win,u Upper limit for indoor/supply humidity ratio g/kg

$\mathrm{W}_{\text {out }} \quad$ Ambient (or outdoor) humidity ratio $\mathrm{g} / \mathrm{kg}$

WBR Wet bulb temperature ${ }^{\circ} \mathrm{C}$

\section{References}

Allard, F. 1998. Natural ventilation in buildings: a design handbook. James and James Ltd : London.

Artmann, N., Manz, H., and P. Heiselberg. 2007. “Climatic potential for passive cooling of buildings by night-time ventilation in Europe.” Applied Energy 84 (2) : 187-201.

ASHRAE (American Society of Heating, Refrigerating and Air-Conditioning Engineers). 2009a. Fundamentals volume of ASHRAE Handbook. Chapter 1: Psychrometrics.

ASHRAE (American Society of Heating, Refrigerating and Air-Conditioning Engineers). 2009b. Fundamentals volume of ASHRAE Handbook. Chapter 9: Thermal Comfort.

ASHRAE (American Society of Heating, Refrigerating and Air-Conditioning Engineers). 2013. Standard 55: Thermal environmental conditions for human occupancy. 
Axley J.W. 2001. Application of Natural Ventilation forU.S. Commercial Buildings Climate Suitability Design Strategies \& Methods Modeling Studies, NIST GCR-01820.

Bauman, F.S. 1999. “Giving occupants what they want: guidelines for implementing personal environmental control in your buildings.” In: Proceedings of World Workplace 99. Los Angeles.

Beattie, C.I., Longhurst, J.W.S., and NK. Woodfield. 2001. “Air quality management: evolution of policy and practice in the UK as exemplified by the experience of English local government.” Atmospheric Environment 32 (8) : 14791490.

Berglunt L.G. 1998. “Comfort and Humidity.” ASHARE Journal 40 (8) : 35-41. Bourgeois, D., Potvin A., and Haghighat F. 2000. "Hybrid Ventilation of Canadian Non-Domestic Buildings: A Procedure For Assessing IAQ, Comfort and Energy Conservation.” In: Proceedings of RoomVent 2000. Reading. Borgeson, S. and G. Brager. 2011. "Comfort standards and variations in exceedance for mixed-mode buildings.” Building Research \& Information 39 (2) : 118-133. Brager, G., and L. Baker. 2008. “Occupant satisfaction on mixed-mode buildings.” In: Proceedings of Air Conditioning and the Low Carbon Cooling Challenge. Cumberland Lodge, Windsor.

BRECSU (Building Research Energy Conservation Support Unit). 2000. Energy consumption guide 19: energy use in offices. BRECSU : Garston.

CEN (Comité Européen de Normalisation). 2007. Standard EN 15251: Indoor environmental input parameters for design and assessment of energy performance of buildings addressing indoor air quality, thermal environment, lighting and acoustics. 
CIBSE (Chartered Institution of Building Services Engineers). 1998. Good Practice Guide 237 - Natural Ventilation in Non-Domestic Buildings: A Guide for Designers. CIBSE : London.

CIBSE (Chartered Institution of Building Services Engineers). 2005. Application manual AM10: natural ventilation in non-domestic buildings. CIBSE : London. de Dear, R., G. Brager, and D. Cooper.1997. Developing an adaptive model of thermal comfort and preference. ASHRAE RP-884 Final Report. de Dear, R., and G. Brager. 1998. “Developing an adaptive model of thermal comfort and preference.” ASHRAE Transactions 104 (1) : 145-167. de Dear R. 2010. “Thermal comfort in natural ventilation - A neurophysiological hypothesis.” In: Proceedings of Adapting to Change: New Thinking on Comfort. Cumberland Lodge, Windsor.

de Dear R. 2011. "Revisiting an old hypothesis of human thermal perception: alliesthesia.” Building Research \& Information 39 (2) : 108-117. Emmerich, S.J., Dols, W.S., and J.W. Axley. 2001. Natural ventilation review and plan for design and analysis tools. NISTIR 6781, National Institute of Standards and Technology.

Emmerich, S.J., Polidoro, B., and J.W. Axley. 2011. "Impact of adaptive thermal comfort on climatic suitably of natural ventilation in office buildings.” Energy and Buildings 43 (9) : 2101-2107

Etheridge, D., and Sandberg M. 1996. Building Ventilation: Theory and Measurement. Wiley.

Etheridge, D. 2011. Natural Ventilation of Buildings: Theory, Measurement and Design. Wiley. 
Fabrizio, E., Corgnati, S.P., Causone, F., and M. Filippi. 2012. “Numerical comparison between energy and comfort performances of radiant heating and cooling systems versus air systems.” HVAC\&R Research 18 (4) : 692-708. Fanger, P.O. 1970. Thermal Comfort: Analysis and Applications in Environmental Engineering. Danish Technical Press : Copenhangen.

Fountain, M.E., Arens, E.A., Xu, T., Bauman, F.S., and Oguru, M. 1999. “An Investigation of Thermal Comfort at High Humidities.” ASHRAE Transactions 105 (2) : 94-103.

Frontczak, M., Schiavon, S., Goins, J., Arens, E., Zhang, H., and P. Wargocki. 2012. “Quantitative relationship between occupant satisfaction and satisfaction aspects of indoor environmental quality and building design.” Indoor Air 22 (2) : 119-131. Gagge, A.P., Stolwijk, J.A.J., and Nishi, Y. 1971. “An effective temperature scale based on a simple model of human physiological regulatory response.” ASHRAE Transactions 77(1) : 247-262.

Gagge, A.P., Fobelets, A.P., and Berglund, L.G. 1986. “A standard predictive index of human response to the thermal environment.” ASHRAE Transactions 92 (2) 709731.

Germano M. 2007. “Assessing the natural ventilation potential of the Basel region.” Energy and Buildings 39 (11) : 1159-1166.

Ghiaus, C., and F. Allard. 2006. “Potential for free-cooling by ventilation.” Solar Energy 80 (4) :402-413.

Givoni, B. 1969. Man, climate and architecture, Elsevier : Amsterdam. Givoni, B. 1998. Climate considerations in building and urban design, Van Nostrand Reinhold : New York. 
Gu L. 2007. “Airflow network modelling in EnergyPlus.” In: Proceedings of Building Simulation, Beijing, China.

Huizenga, C., Abbaszadeh, A., Zagreus, L., and E. Arens. 2006. "Results of large indoor environmental quality survey.” In: Proceeding of Healthy Buildings. Lisbon. Humphreys, M.A., and J.F. Nicol. 1998. "Understanding the adaptive approach to thermal comfort.” ASHRAE Transactions 104 (1B ): 991-1004.

ISO (International Organization for Standardization). 2005. Standard ISO 7730:

Ergonomics of the thermal environment - Analytical determination and interpretation of thermal comfort using calculation of the PMV and PPD indices and local thermal comfort criteria.

Janssen J.E. 1999. “The history of ventilation and temperature control.” ASHRAE Journal 41 (10) : 47-52.

Kanada, M., Fujita, T., Fujii, M., amd S. Ohnishi. 2013. “The long-term impacts of air pollution control policy: historical links between municipal actions and industrial energy efficiency in Kawasaki City, Japan.” Journal of Cleaner Production 58 (1) : 92-101.

Lomas, K.L., Fiala, D., Cook, M.J. and Cropper, P.C. 2004. "Building bioclimatic charts for non-domestic buildings and passive downdraught evaporative cooling.” Building and Environment 39 : 661-671.

Mansy, K. 2006. “Five locations to represent world climates.” In: Proceeding of the 23rd Conference on Passive and Low Energy Architecture (PLEA). Geneva.

McCartney, K.J., and J.F. Nicol. 2002. “Developing and adaptive control algorithm for Europe.” Energy and Buildings 34 (6) : 623-635.

McConahey, E. 2008. "Finding the right mix.” ASHARE Journal 50 (9) : 36-48 
Mendell, M.J., Fisk, W.J., Smith, A.H. Seavery, W., Hodgson, A.T., Daisey, J.M., Smith, D.F., Macher, J.M., and L. Goldman. 1996. "Elevated symptoms prevalence associated with mechanical ventilation in office buildings.” Epidemiology 7 (6) : 583-589 .

Mendell, M.J., and A. Mirer. 2009. "Indoor thermal factors and symptoms in office workers: findings from the U.S. EPA base study.” Indoor Air 19 (4) : 291-302.

McGilligan, C., Natarajan, S., and M. Nikolopoulou. 2011. “Adaptive comfort degree-days: a metric to compare adaptive comfort standard and estimate changes in energy consumption for future UK climates.” Energy and Buildings 43 (10) : 27672778.

Nicol, J.F., and M.A. Humphreys. 2002. “Adaptive thermal comfort and sustainable thermal standards for buildings.” Energy and Buildings 34 (6) : 563-572.

Nicol FJ. 2004. “Adaptive thermal comfort standards in the hot-humid tropics.” Energy and Buildings 36 (7) : 628-637.

Nicol, J.F., and MA. Humphreys. 2004. “A stochastic approach to thermal comfort—occupant behaviour and energy use in buildings.” ASHARE Transactions $110(2): 554-568$.

Nicol, J.F., and L. Pagliano. 2007. “Allowing for thermal comfort in free-running buildings in the new European standard EN 15251.” In: Proceedings of PALENC. Crete Island, Greece.

Nielsen, P.V., Allard, F., Awbi. H.B., Davidson, L., and A. Schälin. 2007. REHVA

Guidebook 10: computational fluid dynamics in ventilation design. Rehva : Brussels.

Olgyay, V. 1953. Bioclimatic approach to architecture. Building Research Advisory Board. Conf. Report No. 5. National Research Council: Washington, DC. 
Olgyay, V. 1963. Design with climate: bioclimatic approach to architectural regionalism. Princeton University Press : Princeton.

Rohles, F.H., Hayter, R.B., and Milliken, G. 1975. "Effective temperature (ET*) as a predictor of thermal comfort.” ASHRAE Transactions 81(2) : 148-156.

Seppanen, O., and W.J. Fisk. 2002. "Relationship of SBS-symptoms and ventilation systems type in office buildings.” In: Proceedings of Indoor Air 2002. Monterey. Schiavon, S., Hoyt, T., and Piccioli, A. 2014. "Web application for thermal comfort visualization and calculation according to ASHRAE Standard 55.” Building Simulation 7 : 321-334.

Stuart Dols, W., Emmerich S.J., and Polidoro B.J. 2012. LoopDA 3.0 - Natural Ventilation Design and Analysis Software User Guide. NIST Technical Note 1735.

Szokolay, S.V. 2008. Introduction to Architectural Science, Routledge : London and New York.

Turner, S.C. 2011. “What's new in ASHRAE's standard on comfort.” ASHARE Journal 53 (6) : 42-48.

Visitsak, S. 2007. An Evaluation of the Bioclimatic Chart for Choosing Design Strategies for a Thermostatically-Controlled Residence in Selected Climates. PhD Thesis. Texas A\&M University.

Warren P. 2000. Multizone Air flow modelling (COMIS). Summary of IEA Annex 23. IEA : Coventry.

Williams M. 2004. “Air pollution and policy-1952-2002.” Science of the Total Environment 334-335 : 15-20. 
Wyon, D.P., Fang, L., Lagercrantz L. and Fanger P.O. 2006. “Experimental

Determination of the Limiting Criteria for Human Exposure to Low Winter Humidity Indoors (1160-RP)”. HVAC\&R Research 12 (2) : 201-213.

Wood, A., and R. Salib. 2012. Natural ventilation in high-rise office buildings. Abingdon: Routledge. 